\title{
Body Image and Personality in Aesthetic Plastic Surgery: A Case-Control Study
}

\author{
Valentina Elisabetta Di Mattei1,2*, Elena Pagani Bagliacca1, Luca Lavezzari2, \\ Rossella Di Pierro ${ }^{3}$, Letizia Carnelli ${ }^{1}$, Paola Zucchi ${ }^{1}$, Franz Baruffaldi Preis ${ }^{1,4}$, \\ Lucio Sarno ${ }^{1,2}$ \\ ${ }^{1}$ San Raffaele Hospital, Milan, Italy \\ ${ }^{2}$ University Vita-Salute San Raffaele, Milan, Italy \\ ${ }^{3}$ Department of Psychology, University of Milano Bicocca, Milan, Italy \\ ${ }^{4}$ Orthopaedic Institute Galeazzi, Milan, Italy \\ Email: ${ }^{*}$ dimattei.valentina@hsr.it
}

Received 16 March 2015; accepted 3 April 2015; published April 2015

Copyright (C 2015 by authors and Scientific Research Publishing Inc.

This work is licensed under the Creative Commons Attribution International License (CC BY). http://creativecommons.org/licenses/by/4.0/

(c) (i) Open Access

\begin{abstract}
Introduction: The amount of research on the relationship between plastic surgery and psychological features, such as personality disorders and indexes of body image dissatisfaction, has increased significantly in the last years. Aim: The aim of the present study was to examine these psychological features among Italian patients who underwent aesthetic plastic surgery, testing the mediating role of the mass media influence on the relationship between them and the choice of aesthetic plastic surgery. The Personality Diagnostic Questionnaire 4+ (PDQ-4+) and the Body Uneasiness Test (BUT) were administered to patients who underwent aesthetic plastic surgery ( $N$ = 111) and participants who had no history of aesthetic plastic surgical procedures $(\mathrm{N}=149)$. Results: Results showed that aesthetic patients reported higher indexes of body image disturbance than controls. No significant differences between aesthetic participants and controls were found in all three cluster B personality disorders. Moreover, the effect of body image dissatisfaction on the choice to undergo aesthetic plastic surgery was partially mediated by the influence of mass media. Conclusions: In conclusion, the present study confirmed the importance of body dissatisfaction as a predictor of the choice to undergo aesthetic surgery and highlighted the influence of media messages regarding physical appearance.
\end{abstract}

\section{Keywords}

Body Image Dissatisfaction, Plastic Surgery, Personality Disorders, Mass Media

\footnotetext{
${ }^{*}$ Corresponding author.
}

How to cite this paper: Di Mattei, V.E., Bagliacca, E.P., Lavezzari, L., Di Pierro, R., Carnelli, L., Zucchi, P., Preis, F.B. and Sarno, L. (2015) Body Image and Personality in Aesthetic Plastic Surgery: A Case-Control Study. Open Journal of Medical Psychology, 4, 35-44. http://dx.doi.org/10.4236/ojmp.2015.42004 


\section{Introduction}

In recent years, the amount of research on the relationship between plastic surgery and psychological aspects has increased significantly due to the wide and fast diffusion of these surgical procedures. According to the American Society for Aesthetic Plastic Surgery, there were over 11 million surgical (16.5\%) and nonsurgical (83.5\%) aesthetic procedures performed in the United States in 2013, with an increase of more than $279 \%$ compared with the year 1997 [1]. In 2013, the most frequent aesthetic plastic surgical procedures were liposuction (363,912 procedures, up to $16.3 \%$ compared with 2012), breast augmentation $(323,327$ procedures down $5.2 \%$ compared with 2012), blepharoplasty (161,389 procedures, up 5.4\% compared with 2012) and abdominoplasty (160.077 procedures, up $2.3 \%$ compared with 2012). The majority of patients who underwent cosmetic surgery were female (90.6\%) [1]. Moreover, the majority of patients who underwent surgical procedures were between 35 and 50 years old (39.3\%), followed by 19 to 34 years old (27.2\%), and 51 to 64 years old (23.9\%) [1].

Similarly, the Italian Association of Aesthetic Plastic Surgery reported that 956,500 cosmetic surgical procedures were performed in the last year in Italy [2]: only the $25 \%$ of them were surgical procedures. In the USA, people who undergo aesthetic plastic surgery are predominantly females $(82.2 \%)$, and the most frequent surgical procedures are liposuction (44,464 procedures, down 15\% compared with 2012), breast augmentation (33,481, up 6.4\% compared with 2012) and blepharoplasty (31,982 procedures, up 55.4\% compared with 2012). Moreover, the majority of female patients were aged 35 to 50 years old (42\%), followed by 19 to 34 years old (25.4\%), and 51 to 64 years old $(25.2 \%)$ [2].

The popularity of cosmetic medical treatment can be attributed to several factors [3] [4]. Among these are the evolution of safer (minimally invasive procedures), and the increased attention of mass media on beauty and cosmetic surgery, and on the patients themselves [4]. In a sense, as suggested by Sarwer and colleagues [5], more and more people aim to combat their dissatisfaction with appearance through aesthetic surgery [5].

A large body of research has shown that dissatisfaction with one's body image is the main factor motivating people to undergo cosmetic surgical procedures [6] [7].

A number of studies suggest that body image dissatisfaction is higher among patients seeking cosmetic surgery than people not interested in plastic surgery [8] [9]. Nevertheless, it seems that there are some differences in body image dissatisfaction levels among different types of cosmetic plastic surgery requested: patients who undergo rhytidectomy and blepharoplasty show significantly less dissatisfaction than patients undergoing rhinoplasty [10] [11]. In general, greater body image dissatisfaction seems to be associated with more favorable attitudes towards cosmetic surgery [12] and it is generally focused on the part of the body that will be improved by cosmetic surgery, instead of overall body image [9] [13] [14].

Extreme body image dissatisfaction is the main feature of several psychopathologies including Body Dismorphic Disorder (BDD) [15]. A recent review by Mallick and colleagues [16] has shown a high prevalence of BDD among American and European patients seeking aesthetic plastic surgery [16]. The study finds that BDD occurs in $7 \%-8 \%$ of patients seeking aesthetic plastic surgery in the USA and in 3\% - 6\% of European patients, whereas its prevalence is approximately $1 \%-2 \%$ among the general population $(2.4 \%$ in USA and $1.7 \%-1.8 \%$ in Europe) [17]-[19]. Finally, other studies using less strict diagnostic criteria estimate a prevalence of BDD ranging between $13 \%$ and $28 \%$ among aesthetic plastic patients [20]-[22].

Research on body image distortions has shown that exposure to mass media is frequently associated with body image dissatisfaction among both adults [23]-[25] and very young girls [26]-[28].

The majority of media messages generally result in negative self-evaluations because of the difficulty in achieving the ideals of beauty promoted [29] [30].

Lastly, according to the literature, among patients seeking cosmetic surgery, up to $47.7 \%$ meet criteria for a mental disorder [31] [32]. In particular, some studies highlight a high prevalence of cluster B personality disorders (PDs) among patients undergoing aesthetic plastic surgery [16] [17]. The most frequently cluster B PDs among these patients are Narcissistic Personality Disorder, which occurs in $25 \%$ of patients seeking cosmetic surgery and Histrionic Personality Disorders in $9.7 \%$ of the cases [16], whereas the prevalence rates of cluster B PDs among general population is about $1.5 \%[33]$.

Considering these findings, the aim of the present study is to examine psychological features (PDs and indexes of body image dissatisfaction) among Italian patients who undergo aesthetic plastic surgery. We expect that patients who undergo aesthetic plastic surgery will report higher scores in both PDs and indexes of body image dissatisfaction than community participants. Finally, we test how the relationship among these psychological 
features and the choice to undergo aesthetic plastic surgery may be affected by the influence of mass media.

In fact, it can be important to understand if the media can influence the choice to undergo plastic surgery. For this reason, we hypothesize that the influence of mass media may have a mediator role on the connection between PDs or indexes of body image dissatisfaction and the choice to undergo aesthetic plastic surgery.

\section{Materials and Methods}

\subsection{Participants}

The study involved two samples of participants: 111 patients who underwent aesthetic plastic surgery and 149 community participants with no history of plastic surgery procedures. Inclusion criteria for all participants were: 1) patients had to be between 20 and 70 years old; 2) patients had to be Italian native speakers.

The first sample of participants was composed of patients consecutively admitted to a general plastic surgery ward of the Galeazzi Orthopaedic Institute, I.R.C.C.S., and of the San Raffaele Hospital (Milan, Italy). Participants from the second sample were invited to participate in this study through announcements and postings on Internet websites.

All participants voluntarily decided to complete self-reports; before the questionnaires were given directly to the participants, all the patients were asked to sign the informed consent form to participate in the study, ensuring anonymity with regards to the data.

The control group was selected through an online survey and these participants' anonymity was also guaranteed. The first sample was composed by 111 patients who underwent aesthetic plastic surgery ( 99 females, $89.2 \%$ ) with an overall mean age of 33.58 (range $20-57$; $\mathrm{SD}=8.29$ ). The most frequent aesthetic surgery procedures in the sample were rhinoplasty (34.3\%), breast augmentation $(30.6 \%)$, liposuction $(20.4 \%)$ and breast reduction $(14.8 \%)$. The majority of patients in our sample were single $(45.5 \% ; \mathrm{N}=50)$ or married $(41.8 \% ; \mathrm{N}=$ $46)$, and $12.7 \%(\mathrm{~N}=14)$ of patients were separated or divorced. The majority of patients were employed $(65.5 \%$; $\mathrm{N}=72), 7.3 \%(\mathrm{~N}=8)$ were unemployed, while $14.5 \%$ of patients were housewives $(\mathrm{N}=16)$ and $12.7 \%(\mathrm{~N}=14)$ were students. The majority of patients had a high school degree $(69.1 \% ; \mathrm{N}=76)$, although $30 \%(\mathrm{~N}=33)$ of participants had a master degree or higher tertiary education, and one patient had a middle school graduation $(0.9 \%)$. No data were available on the level of education for one patient.

The second sample was composed of 149 community participants ( $85.8 \%$ females; $14.2 \%$ males) with an overall mean age of 29.60 (range $20-56 ; \mathrm{SD}=8.09)$. The majority of participants were single $(66.4 \% ; \mathrm{N}=99)$, whereas $29.5 \%(\mathrm{~N}=44)$ of participants were married, and $4 \%(\mathrm{~N}=6)$ were divorced or widowed. The majority of participants were employed $(67.7 \% ; \mathrm{N}=101), 26.8 \%(\mathrm{~N}=40)$ of participants were students, while $4.0 \%$ were unemployed $(\mathrm{N}=6)$, and $1.3 \%$ were housewives $(\mathrm{N}=2)$. Finally, the majority of participants had a master degree or higher tertiary education $(75.8 ; \mathrm{N}=113)$, whereas $22.1 \%$ had a high school degree $(\mathrm{N}=33)$, and three participants $(2 \%)$ had a middle school graduation.

No gender differences were found between the two groups of participants $\left(\chi^{2}=0.28 ; p=0.60\right)$.

\subsection{Measures}

Features connected to body image perception were collected. We asked participants whether they had a specific prototype of beauty, how much mass media influenced one's body perception through the question "Considering the definition of the ideal body image, how is important the image provided by the mass media" (assessed by 11 points Likert scale from 0 to 10), and which beauty behaviors they engaged in. The presence of a prototype of beauty was a dichotomous variable (true/false); whereas the influence of mass media was measured on a Likert scale ranging from 0 (not at all) to 10 (totally). The beauty behaviors included the use of cosmetics, being on diet, and going to the gym. They were measured on a true/false format.

The Personality Diagnostic Questionnaire 4+ (PDQ-4+) [34] [35] is a personality self-report measure composed of 99 true/false items. The PDQ-4 is based on the DSM-IV [36]: it assesses the 10 personality disorders of the DSM-IV, and it includes the personality disorders such as passive-aggressive and depressive that were included in the appendix of the manual. The results from the screening test were intended to provide an indication of key features of each personality disorder. For the purpose of the present study, only cluster B personality disorders (with the exception of antisocial disorder) were considered. The Italian version of the PDQ-4+ showed acceptable internal consistency coefficients for all the cluster B scales (range $\alpha=0.54-0.70$ ). 
The Body Uneasiness Test (BUT) [37] [38] is a 71-item self-report measure that assesses body image disturbances. It is divided into two parts:

- BUT-a, consisting of 34 clinical items;

- BUT-b, consisting of 37 items regarding dissatisfaction with body parts.

Items are scored on a 6-point scale, ranging from 0 (never) to 5 (always), with higher scores indicating greater body uneasiness. In addition to the overall rating, other indexes could be obtained from the BUT such as the Global Severity Index (GSI) - which is calculated dividing BUT-a scores by BUT-a item number $(\mathrm{N}=34)$. Moreover, BUT is divided into five subscales: Weight Phobia (WP), Body Image Concerns (BIC), Avoidance (A), Compulsive Self-Monitoring (CSM), and Depersonalization (D). Finally, the BUT-b id described by two indexes: the Positive Symptom index (PST), which is the amount of all the items with non-zero responses, and the Positive Symptom Distress Index (PSDI), which is the sum of the values of the items receiving non-zero responses divided by the PST. The Italian version of the BUT showed good internal consistency coefficients for all the scales (range $\alpha=0.64-0.84$ ).

\subsection{Statistical Analyses}

All analyses were performed using SPSS 18.0 [39]. Descriptive statistics were used to describe the socio-demographic and psychological characteristics among the two samples of participants. Chi-Square and ANOVA analyses were conducted to test differences between the two groups of participants with regards to descriptive features, the presence of PDs and indexes of body image disorders. Finally, linear and logistic regressions were conducted to study the relations between body dissatisfaction, the influence of mass media on one's beauty prototype, and the probability of undergoing aesthetic plastic surgery.

\section{Results}

The majority of patients had never undergone aesthetic plastic surgery in the past $(65.1 \% ; \mathrm{N}=71)$. Among those who reported aesthetic plastic surgery in the past, the majority of them reported to have undergone one plastic surgery procedure $(\mathrm{N}=24 ; 63.2 \%)$, the $31.6 \%(\mathrm{~N}=12)$ reported two plastic surgery procedures, and two $39.4 \%$ $(\mathrm{N}=15)$ underwent other plastic surgery procedures. For two patients no data were patients reported three plastic surgery procedures in the past $(1.8 \%)$. Among patients who had undergone plastic surgery in the past, $76.4 \%$ $(\mathrm{N}=29)$ of them underwent the same plastic surgery procedure, and the available on the number and type of aesthetic plastic surgery procedures in the past.

With respect to the choice of the surgeon, the majority of patients selected the surgeon on the basis of showbiz and celebrity choices $(36.9 \% ; \mathrm{N}=41)$. Only a minority of patients chose the surgeon on the basis of other patients' experiences $(25.2 \% ; \mathrm{N}=28)$ or domain expertise $(\mathrm{N}=29 ; 26.1 \%)$. The majority of patients reported that they did not have a prototype of beauty $(86.5 \% ; \mathrm{N}=96)$. Among those who had a prototype $(13.5 \%, \mathrm{~N}=$ $15)$, only three patients $(21.4 \%)$ brought a photograph with them to the appointment with the surgeon.

Regarding the presence of cluster B PDs among the two groups of participants, rates are reported in Table 1.

The results showed no significant differences between the two groups in all the three cluster B personality disorders.

Other, significant group differences were found in the indexes of body image disturbance measured by the BUT (Table 2). As reported in Table 2, all the indexes were significantly higher in the group of patients who underwent aesthetic plastic surgery compared to the community participants.

When effects of the BUT indexes are considered together in a multiple regression model, only PSDI and A showed significant effects on the choice to undergo aesthetic plastic surgery (Table 3 ).

Table 1. Presence of cluster B PDs in the group of patients and in the group of community participants.

\begin{tabular}{|c|c|c|c|c|c|c|}
\hline \multirow{2}{*}{ Cluster B PDs } & \multicolumn{2}{|c|}{ Group of patients ${ }^{\mathrm{a}}$} & \multicolumn{4}{|c|}{ Group of community participants ${ }^{b}$} \\
\hline & $\mathrm{N}$ & $\%$ & $\mathrm{~N}$ & $\%$ & $\chi^{2}$ & $\mathrm{p}$ \\
\hline NPD & 0 & 0 & 4 & 2.7 & 1.51 & 0.22 \\
\hline BPD & 0 & 0 & 5 & 3.4 & 2.23 & 0.14 \\
\hline IPD & 0 & 0 & 5 & 3.4 & 2.22 & 0.14 \\
\hline
\end{tabular}

${ }^{\mathrm{a}} \mathrm{N}=111 ;{ }^{\mathrm{b}} \mathrm{N}=149 ; \mathrm{NPD}=$ Narcissistic Personality Disorder; BPD = Borderline Personality Disorder; IPD = Histrionic Personality Disorder. 
Table 2. BUT scales: mean, standard deviations, and differences between the two groups.

\begin{tabular}{|c|c|c|c|c|c|}
\hline \multirow{2}{*}{ BUT indexes } & \multicolumn{2}{|c|}{ Group of patients ${ }^{a}$} & \multicolumn{2}{|c|}{ Group of community participants } & \multirow[b]{2}{*}{$\mathrm{F}$} \\
\hline & M & SD & M & $\mathrm{SD}$ & \\
\hline GSI & 1.20 & 0.64 & 0.87 & 0.66 & $16.07 * *$ \\
\hline WP & 1.81 & 0.93 & 1.40 & 1.03 & $10.78^{* *}$ \\
\hline $\mathrm{BIC}$ & 1.48 & 0.80 & 1.06 & 0.83 & $17.22 * *$ \\
\hline A & .64 & 0.61 & 0.31 & 0.45 & $24.82 *$ \\
\hline CSM & 1.14 & 0.86 & 0.88 & 0.70 & $8.75^{*}$ \\
\hline PSDI & 2.80 & 1.27 & 1.92 & 0.68 & $51.83^{* *}$ \\
\hline
\end{tabular}

${ }^{\mathrm{a}} \mathrm{N}=111 ;{ }^{\mathrm{b}} \mathrm{N}=149 ;$ GSI = Global Severity Index (GSI); WP = Weight Phobia; $\mathrm{BIC}=$ Body Image Concerns; $\mathrm{A}=\mathrm{Avoidance} ; \mathrm{CSM}=\mathrm{Compulsive}$ Self-Monitoring; D = Depersonalization; PSDI = Positive Symptom Distress Index; ${ }^{p} \mathrm{p}<0.05 ; * * \mathrm{p}<0.001$.

Table 3. Multiple logistic regression: effects of the BUT indexes on the choice to undergo surgery.

\begin{tabular}{ccccc}
\hline & B & Exp (B) & Df & $\chi^{2}$ \\
\hline Multiple regression model & - & & 6 & $51.52^{* *}$ \\
PSDI & 0.77 & 2.16 & 1 & $22.54^{* *}$ \\
WP & -0.15 & 0.86 & 1 & 0.36 \\
BIC & 0.09 & 1.09 & 1 & 0.08 \\
A & 0.93 & 2.55 & 1 & $5.72^{*}$ \\
CSM & 0.19 & 1.21 & 1 & 0.77 \\
D & -0.29 & 0.75 & 1 & 0.68 \\
\hline
\end{tabular}

$\mathrm{N}=260 ;$ PSDI = Positive Symptom Distress Index; WP = Weight Phobia; BIC = Body Image Concerns; $\mathrm{A}=\mathrm{Avoidance}$; CSM = Compulsive SelfMonitoring; $\mathrm{D}=$ Depersonalization; ${ }^{*} \mathrm{p}<0.05 ; * * \mathrm{p}<0.001$.

The higher the PSDI was the higher the probability of undergoing aesthetic surgery was $\left(\operatorname{Exp}(B)=2.16, \chi^{2}(1)\right.$ $=22.54 ; \mathrm{p}<0.001)$. Similarly, the higher A was, the higher the probability of undergoing aesthetic surgery was $\left(\operatorname{Exp}(\mathrm{B})=2.55, \chi^{2}(1)=5.72 ; \mathrm{p}<0.05\right)$.

Finally, a mediation model was tested to study whether the relationship between PSDI, A, and the choice to undergo aesthetic plastic surgery is mediated by the mass media influence. Three subjects were excluded from the analyses because of missing values on the mass media influence. The mediation test was conducted separately for PSDI and A. The results showed that the effect of PSDI on the choice to undergo aesthetic plastic surgery is partially mediated by the mass media influence (Figure 1). We tested the significance of this indirect effect using bootstrapping procedures. Unstandardized indirect effects have been computed for each of the 5.000 bootstrapped samples, and the $95 \%$ confidence interval was computed by determining the indirect effects at the 2.5th and 97.5 th percentiles.

The bootstrapped unstandardized indirect effect was 1.15 , and the $95 \%$ confidence interval ranged from 0.05 , 0.29. Thus, the indirect effect of PDSI on aesthetic plastic surgery was statistically significant.

In general, the higher the PSDI was, the higher the probability of aesthetic plastic surgery was. Part of this effect was mediated by mass media: the higher the PSDI was, the more the influence from mass media was, and the more mass media influence was, the higher the probability of undergoing aesthetic plastic surgery was.

Similarly, the results show that the effect of A on the choice to undergo aesthetic plastic surgery was partially mediated by the influence of mass media (Figure 2). We tested the significance of this indirect effect using bootstrapping procedures. Unstandardized indirect effects have been computed for each of the 5.000 bootstrapped samples, and the $95 \%$ confidence interval was computed by determining the indirect effects at the 2.5 th and 97.5 th percentiles. The bootstrapped unstandardized indirect effect was 1.45 , and the $95 \%$ confidence interval ranged from $0.15,0.74$. Thus, the indirect effect of $A$ on aesthetic plastic surgery was statistically significant.

In general, higher body avoidance resulted in higher probability of undergoing aesthetic plastic surgery. Part 


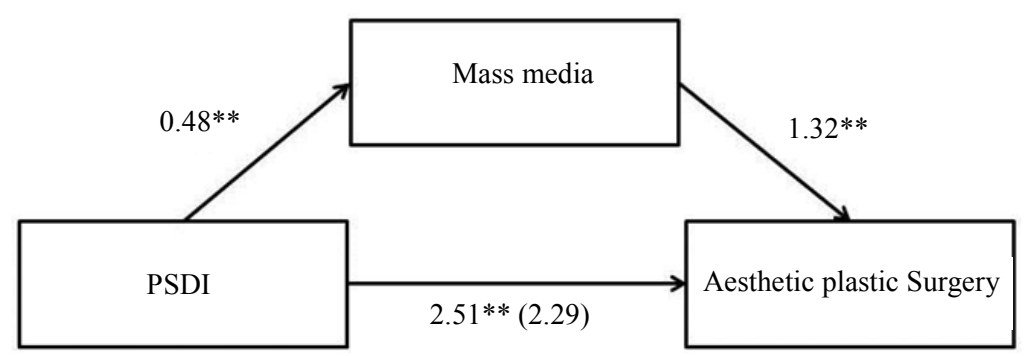

Figure 1. Standardized regression coefficients for the relationship between positive symptom distress index and aesthetic surgery as mediated by mass media. $\mathrm{N}=257$; PSDI = Positive Symptom Distress Index. The standardized regression coefficient between PSDI and aesthetic plastic surgery, controlling for mass media influence, is in brackets. ${ }^{* *} \mathrm{p}<0.001$.

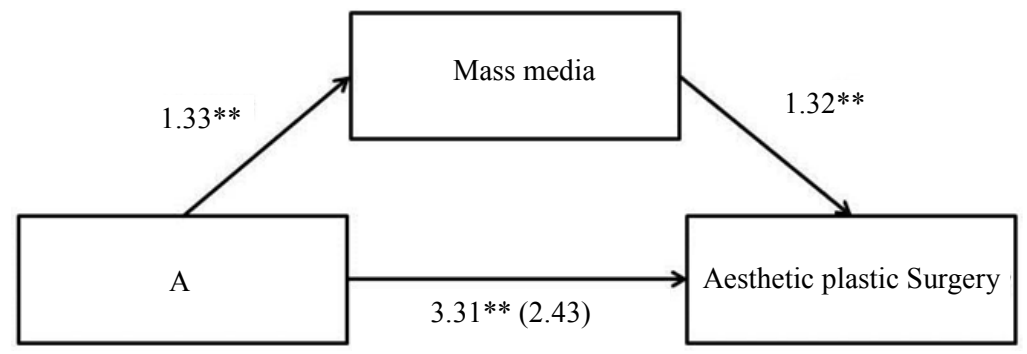

Figure 2. Standardized regression coefficients for the relationship between avoidance and aesthetic surgery as mediated by mass media. $\mathrm{N}=257$; $\mathrm{A}=$ Avoidance. The standardized regression coefficient between avoidance and aesthetic plastic surgery, controlling for mass media influence, is in parentheses. $* * \mathrm{p}<0.001$.

of this effect was mediated by mass media: the higher the body avoidance was the more the mass media influence was, and the more the mass media influence was, the higher the probability of aesthetic plastic surgery was.

\section{Discussion and Conclusions}

The aim of the present study was to examine psychological features (PDs and indexes of body image dissatisfaction) among Italian patients who underwent aesthetic plastic surgery procedures. Moreover, the relationship between these psychological features and the choice to undergo aesthetic plastic surgery was tested in relation to the influence of mass media on one's body perception.

The results of the current study are in line with previous research showing that patients who undergo aesthetic plastic surgery are predominantly females with an overall mean age of 29.60 [1] [2].

The relationships between body image and cosmetic operations have been at the centre of the recent studies. According to Sarwer and Crerand [3], this represents a new generation of research on the psychological aspects of aesthetic plastic surgery, because the main aim of every type of cosmetic surgery is to facilitate the psychosocial functioning of the patient by changing their body image [40].

According to the literature, patients who undergo aesthetic plastic surgery are characterized by high levels of body image dissatisfaction [13] [7] and the presence of pathological personality traits [32] [41] [42]. As regards PDs, many studies have shown that patients who undergo plastic surgery report a greater frequency of cluster B personality disorders, particularly Narcissistic PD, Histrionic PD and Borderline PD, compared with people who do not undergo plastic surgery [16] [41] [43]. Contrary to previous research, results from the present study showed that there were no significant differences between the two groups of participants in all the three cluster B personality disorders. After all, researches are discordant on this topic: some studies suggest that the presence of PDs may not have a direct role in the choice of aesthetic plastic surgery, while many studies highlight that an abnormal personality profile may represent one of the predisposing conditions for the development of distortions of body image representation, which becomes a strong motivation for plastic surgery [44] [45]. 
On the other hand, body image dissatisfaction is considered to be a primary motivation for aesthetic plastic surgery [46] [47]. In line with previous studies, results from the present study showed that patients reported higher preoperative body image dissatisfaction than community participants [48] [49]. Moreover, results showed that the probability of undergoing aesthetic plastic surgery was affected by two indexes of body image disturbance: avoidance and uneasiness with parts of the body. Specifically, our results suggested that: the more avoidance behaviors related to body image people engaged in, the higher the probability of choosing aesthetic plastic surgery was; the greater the parts of the body people were uneasy with, the higher the probability of choosing to undergo aesthetic plastic surgery was.

Finally, recent research has showed that aesthetic surgery programs on television, surgeon focused-shows, patient reality TV-shows, beauty magazines, advertisements of celebrities who have shared their experiences, movies and the internet have likely contributed to the growth of cosmetic surgery [25]. With respect to this, the present study examined the relationship between body dissatisfaction, the mass media influence on one's body perception, and aesthetic plastic surgery. Confirming findings from Block and Sarwer [25], the present study showed that the influence of mass media partially mediated the effect of avoidance and uneasiness on the choice of aesthetic plastic surgery. Other previous studies have found a link between body dissatisfaction, exposure to media and cosmetic surgery [23] [50]-[52]. Markey and Markey [50] demonstrated that women's body dissatisfaction significantly predicts their interest in cosmetic surgery; moreover, they found that women who were more influenced by the media about physical appearance were also more likely to desire cosmetic surgery.

The results of the present study can be better understood in the context of the study's limitations. Firstly, the PDQ4+, widely used for the screening of Personality Disorders, cannot be considered the standard in the diagnosis of Personality Disorders because it is a self-report measure and it has shown to generate a high percentage of false positives [35] [53]. It is possible that the presence of cluster B PDs among participants was overestimated, and further studies should administered other measurement instruments as the SCID-II to evaluate the prevalence rates of cluster B PDs among Italian patients who undergo aesthetic plastic surgery. Moreover, there was gender imbalance within the two samples of participants. However, the proportion between females and males was in line with previous studies on aesthetic plastic surgery and it mirrors the nature of the phenomenon. Finally, age difference was found between the two groups of participants. Despite this, it did not affect our results. Indeed, younger age might be associated with higher body dissatisfaction, but our results showed that the body dissatisfaction was higher among patients than among community participants. Finally, the present study evaluated the mass media influence through a direct question. Further studies should use self-report measures of mass media influence that are validated. In conclusion, the present study confirmed the importance of body dissatisfaction as a predictor of in the choice to undergo aesthetic surgery [50] and highlighted the influence of media messages regarding physical appearance. One of the main implications of the present study regards the postoperatory phase. Indeed, findings from the present study suggested that the choice to undergo aesthetic plastic surgery is not totally explained by body dissatisfaction, and that it is also affected by the influence of mass media on one's body perception. In this sense, it is possible that the association between body dissatisfaction and mass media influence we found might condition the post-operatory satisfaction of the patient. In the future, it would be interesting to study this effect. As suggested by Sykes, the goal of plastic surgery is to satisfy the patient [54]. Despite this, satisfaction of plastic surgery patients has often related to motivations and psychological characteristics. Assessing these features may help surgeons to decide which patients could be good psychological candidates for surgery [6] [54].

\section{References}

[1] American Society for Plastic Surgery (ASAPS) (2014) Cosmetic Surgery National Data Bank. Statistics. 2013 Statistics, New York.

[2] Italian Association for Aesthetic Plastic Surgery (AICPE) (2014) Cosmetic Surgery National Data Bank. Statistics. 2013 Statistics.

[3] Sarwer, D.B. and Crerand, C.E. (2004) Body Image and Cosmetic Medical Treatments. Body Image, 1, 99-111. http://dx.doi.org/10.1016/S1740-1445(03)00003-2

[4] Sarwer, D.B., Magee, L. and Clark, V.L. (2003) Physical Appearance and Cosmetic Medical Treatments: Physiological and Sociocultural Influences. Journal of Cosmetic Dermatology, 2, 29-39. http://dx.doi.org/10.1111/j.1473-2130.2003.00003.x

[5] Sarwer, D.B., Grossbart, T.A. and Didie E.R. (2003) Beauty and Society. In: Kaminer, M.S., Dover, J.S. and Arndt, A., 
Eds., Atlas of Cosmetic Surgery. Saunders, Philadelphia, 48-59.

[6] Di Mattei, V.E., Pagani Bagliacca, E., Ambrosi, A., et al. (2014) The Impact of Cosmetic Plastic Surgery on Body Image and Psychological Well-Being: A Preliminary Study. International Journal of Psychological Research \& Therapeutics, 1, 103.

[7] Henderson-King, D. and Henderson-King, E. (2005) Acceptance of Cosmetic Surgery: Scale Development and Validation. Body Image, 2, 137-149. http://dx.doi.org/10.1016/j.bodyim.2005.03.003

[8] Bolton, M.A., Pruzinsky, T., Cash, T.F., et al. (2003) Measuring Outcomes in Plastic Surgery: Body Image and Quality of Life in Abdominoplasty Patients. Plastic \& Reconstructive Surgery, 112, 619-625. http://dx.doi.org/10.1097/01.PRS.0000070972.57000.08

[9] Didie, E.R. and Sarwer, D.B. (2003) Factors That Influence the Decision to Undergo Cosmetic Breast Augmentation Surgery. Journal of Women's Health, 12, 241-253. http://dx.doi.org/10.1089/154099903321667582

[10] Sarwer, D.B., LaRossa, D., Bartlett, S.P., et al. (2003) Body Image Concerns of Breast Augmentation Patients. Plastic \& Reconstructive Surgery, 112, 83-90. http://dx.doi.org/10.1097/01.PRS.0000066005.07796.51

[11] Sarwer, D.B., Whitaker, L.A., Wadden, T.A. and Pertschuk, M.J. (1997) Body Image Dissatisfaction in Women Seeking Rhytidectomy or Blepharoplasty. Aesthetic Surgery Journal, 17, 230-234. http://dx.doi.org/10.1016/S1090-820X(97)80004-0

[12] Sarwer, D.B., Cash, T.F., Magee, L., Williams, E.F., Thompson, J.K., Roehrig, M., et al. (2005) Female College Students and Cosmetic Surgery: An Investigation of Experiences, Attitudes, and Body Image. Plastic and Reconstructive Surgery, 115, 931-938. http://dx.doi.org/10.1097/01.PRS.0000153204.37065.D3

[13] Sarwer, D.B., Wadden, T.A., Pertschuk, M.J. and Whitaker, L.A. (1998) The Psychology of Cosmetic Surgery: A Review and Reconceptualization. Clinical Psychology Review, 18, 1-22. http://dx.doi.org/10.1016/S0272-7358(97)00047-0

[14] Von Soest, T., Kvalem, I.L., Skolleborg, K.C. and Roald, H.E. (2006) Psychosocial Factors Predicting the Motivation to Undergo Cosmetic Surgery. Plastic and Reconstructive Surgery, 117, 51-62. http://dx.doi.org/10.1097/01.prs.0000194902.89912.f1

[15] Castle, D.J. and Phillips, K.A. (2002) Disorders of Body Image. Wrightson Biomedical Publishing, Philadelphia.

[16] Mallick, F., Howard, J. and Koo, J. (2008) Understanding the Psychology of the Cosmetic Patients. Dermatologic Therapy, 21, 47-53. http://dx.doi.org/10.1111/j.1529-8019.2008.00169.x

[17] American Psychiatric Association (2013) Diagnostic and Statistical Manual of Mental Disorders. 5th Edition, Washington DC.

[18] Sarwer, D.B. and Crerand, C.E. (2008) Body Dysmorphic Disorder and Appearance Enhancing Medical Treatments. Body Image, 5, 50-58. http://dx.doi.org/10.1016/j.bodyim.2007.08.003

[19] Gunstad, J. and Phillip, K.A. (2003) Axis I Comorbidity in Body Dysmorphic Disorder. Comprehensive Psychiatry, 44, 270-276. http://dx.doi.org/10.1016/S0010-440X(03)00088-9

[20] Biby, E.L. (1998) The Relationship between Body Dysmorphic Disorder and Depression, Self-Esteem, Somatization, and Obsessive-Compulsive Disorder. Journal of Clinical Psychology, 54, 489-499. http://dx.doi.org/10.1002/(SICI)1097-4679(199806)54:4<489::AID-JCLP10>3.0.CO;2-B

[21] Castle, D.J., Honigman, R.J. and Phillips, K.A. (2002) Does Cosmetic Surgery Improve Wellbeing? Medical Journal of Australia, 176, 601-604.

[22] Katharine, A. and Phillips, M.D. (2006) The Presentation of Body Dysmorphic Disorder in Medical Settings. Primary Psychiatry, 13, 51-59.

[23] Markey, C.N. (2006) Culture and the Development of Eating Disorders: A Tripartite Model. Eating Disorders, 12, 139-156. http://dx.doi.org/10.1080/10640260490445041

[24] Lev-Ari, L., Baumgarten-Katz, I. and Zohar, A. (2014) Mirror, Mirror on the Wall: How Women Learn Body Dissatisfaction. Eating Behaviors, 15, 397-402. http://dx.doi.org/10.1016/j.eatbeh.2014.04.015

[25] Block, A.R. and Sarwer, D.B. (2013) Presurgical Psychological Screening: Understanding Patients, Improving Outcomes. American Psychological Association, Washington DC. http://dx.doi.org/10.1037/14035-000

[26] Anschutz, D., Engels, R.C.M.E. and Van Strien, T. (2012) Increased Body Satisfaction after Exposure to Thin Ideal Children's Television in Young Girls Showing Thin Ideal Internalization. Psychology \& Health, 27, 603-617. http://dx.doi.org/10.1080/08870446.2011.613470

[27] Anschutz, D.J., Spruijt-Metz, D., Van Strien, T. and Engels, R.C.M.E. (2011) The Direct Effect of Thin Ideal Focused Adult Television on Young Girls' Ideal Body Figure. Body Image, 8, 26-33. http://dx.doi.org/10.1016/j.bodyim.2010.11.003 
[28] Calado, M., Lameiras, M., Sepulveda, A.R., Rodriguez, Y. and Carrera, M.V. (2011) The Association between Exposure to Mass Media and Body Dissatisfaction among Spanish Adolescents. Women's Health Issues, 21, 390-399. http://dx.doi.org/10.1016/j.whi.2011.02.013

[29] Henderson-King, D., Henderson-King, E. and Hoffman, L. (2001) Media Images and Women's Self Evaluations: Social Context and Importance of Attractiveness as Moderators. Personality and Social Psychology Bulletin, 27, 14071416. http://dx.doi.org/10.1177/01461672012711002

[30] Lew, A., Mann, T., Myers, H., Taylor, S. and Bower, J. (2007) Thin Ideal Media and Women's Body Dissatisfaction: Prevention Using Downward Social Comparison on Non-Appearance Dimensions. Sex Roles, 57, 543-556. http://dx.doi.org/10.1007/s11199-007-9274-5

[31] Belli, H., Belli, S., Ural, C., Akbudak, M., Oktay, M.F., Akyuz Cim, E.F., et al. (2013) Psychopathology and Psychiatric Co-Morbidities in Patients Seeking Rhinoplasty for Cosmetic Reasons. West Indian Medical Journal, 62, 481-486.

[32] Ishigooka, J., Iwao, M., Suzuki, M., Fukuyama, Y., Murasaki, M. and Miura, S. (1998) Demographic Features of Patients Seeking Cosmetic Surgery. Psychiatry and Clinical Neurosciences, 52, 283-287. http://dx.doi.org/10.1046/j.1440-1819.1998.00388.x

[33] Huang, Y., Kotov, R., De Girolamo, G., Preti, A., Angermeyer, M., Benjet, C., et al. (2009) DSM-IV Personality Disorders in the WHO World Mental Health Surveys. The British Journal of Psychiatry, 195, 46-53. http://dx.doi.org/10.1192/bjp.bp.108.058552

[34] Hyler, S.E. (1994) PDQ-4+ Personality Diagnostic Questionnaire-4+. New York State Psychiatric Institute, New York.

[35] Fossati, A., Maffei, C., Bagnato, M., Donati, D., Donini, M., Fiorilli, M., et al. (1998) Criterion Validity of the Personality Diagnostic Questionnaire 4+ (PDQ4+) in a Mixed Psychiatric Sample. Journal of Personality Disorders, 2, $172-$ 178. http://dx.doi.org/10.1521/pedi.1998.12.2.172

[36] American Psychiatric Association (1994) Diagnostic and Statistical Manual of Mental Disorders. 4th Edition, Washington DC.

[37] Cuzzolaro, M., Vetrone, G., Marano, G. and Garfinkel, P.E. (2006) The Body Uneasiness Test (BUT): Development and Validation of a New Body Image Assessment Scale. Eating and Weight Disorders, 11, 1-13. http://dx.doi.org/10.1007/BF03327738

[38] Marano, G., Cuzzolaro, M., Vetrone, G., Garfinkel, P.E., Temperilli, F., Spera, G., et al. (2007) Validating the Body Uneasiness Test (BUT) in Obese Patients. Eating and Weight Disorders, 12, 70-82.

http://dx.doi.org/10.1007/BF03327581

[39] SPSS Inc. (2009) PASW Statistics for Windows. Version 18.0, SPSS Inc., Chicago.

[40] Pruzinsky, T. (1993) Psychological Factors in Cosmetic Plastic Surgery: Recent Developments in Patient Care. Plastic Surgical Nursing, 13, 64-69. http://dx.doi.org/10.1097/00006527-199301320-00003

[41] Napoleon, A. (1993) The Presentation of Personalities in Plastic Surgery. Annals of Plastic Surgery, 31, $193-208$. http://dx.doi.org/10.1097/00000637-199309000-00001

[42] Bellino, S., Paradiso, E., Zizza, M., et al. (2004) Body Dysmorphic Disorder: A Critical Review. Italian Journal of Psychopathology, 10, 237-253.

[43] Shridharani, S.M., Magarakis, M., Manson, P.N. and Rodriguez, E.D. (2010) Psychology of Plastic and Reconstructive Surgery: A Systematic Clinical Review. Plastic and Reconstructive Surgery, 126, 2243-2251. http://dx.doi.org/10.1097/PRS.0b013e3181f445ae

[44] Maffei, C. and Fossati, A. (1997) I disturbi di personalità: Prospettive della ricerca in psicologia clinica per la prassi medica generale. Ricerche di Psicologia, 1, 317-327.

[45] Bellino, S., Zizza, M., Paradiso, E., et al. (2003) Body Dysmorphic Disorder and Personality Disorders: A Clinical Investigation in Patients Seeking Cosmetic Surgery. Italian Journal of Psychopathology, 9, 149-156.

[46] Sarwer, D.B. (2007) The Psychological Aspects of Cosmetic Breast Augmentation. Plastic and Reconstructive Surgery, 120, 110S-117S. http://dx.doi.org/10.1097/01.prs.0000286591.05612.72

[47] Sarwer, D.B., Crearand, C.E. and Gibbons, L.M. (2005) Body Dysmorphic Disorder. In: Nahai, F., Ed., The Art of Aesthetic Surgery, Quality Medical, St Louis, 33-57.

[48] Frederick, D.A., Lever, J. and Peplau, L.A. (2007) Interest in Cosmetic Surgery and Body Image: Views of Men and Women across the Lifespan. Plastic and Reconstructive Surgery, 120, 1407-1415. http://dx.doi.org/10.1097/01.prs.0000279375.26157.64

[49] Simis, K.J., Verhulst, F.C. and Koot, H.M. (2001) Body Image, Psychosocial Functioning, and Personality: How Different Are Adolescents and Young Adults Applying for Plastic Surgery? Journal of Child Psychology and Psychiatry, 42, 669-678. http://dx.doi.org/10.1111/1469-7610.00762 
[50] Markey, C. and Markey, P. (2009) Correlates of Young Women's Interest in Obtaining Cosmetic Surgery. Sex Roles, 61, 158-166. http://dx.doi.org/10.1007/s11199-009-9625-5

[51] Cafri, G., Yamamiya, Y. and Brannick, M. (2005) The Influence of Sociocultural Factors on Body Image: A Meta-Analysis. Clinical Psychology: Science and Practice, 12, 421-433. http://dx.doi.org/10.1093/clipsy.bpi053

[52] Delinsky, S.S. (2005) Cosmetic Surgery: A Common and Accepted form of Self-Improvement? Journal of Applied Social Psychology, 35, 2012-2028. http://dx.doi.org/10.1111/j.1559-1816.2005.tb02207.x

[53] Wilberg, T., Dammen, T.F. and Riis, S. (2000) Comparing Personality Diagnostic Questionnaire-4+ with Longitudinal, Expert, All Data (LEAD) Standard Diagnoses in a Sample with a High Prevalence of Axis I and Axis II Disorders. Comprehensive Psychiatry, 41, 295-302. http://dx.doi.org/10.1053/comp.2000.0410295

[54] Sykes, J.M. (2009) Managing the Psychological Aspects of Plastic Surgery Patients. Current Opinion in Otolaryngology \& Head and Neck Surgery, 17, 321-325. http://dx.doi.org/10.1097/MOO.0b013e32832da0f9 